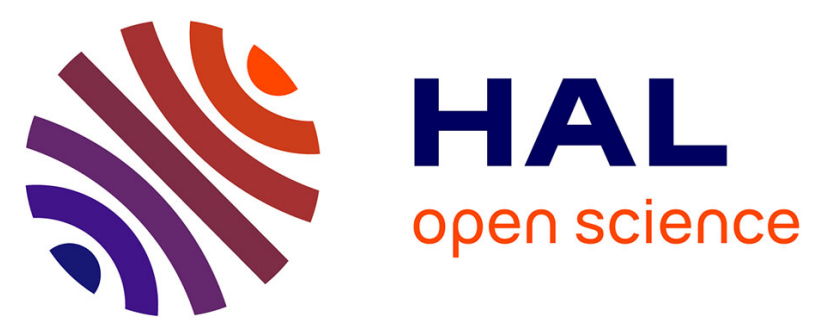

\title{
A fatigue life prediction method of adhesively bonded joints based on visco-elastic and visco-plastic behavior: application under cyclic shear loading
}

Pierre Bidaud, Romain Créac'Hcadec, Pierre Jousset, David Thevenet

\section{- To cite this version:}

Pierre Bidaud, Romain Créac'Hcadec, Pierre Jousset, David Thevenet. A fatigue life prediction method of adhesively bonded joints based on visco-elastic and visco-plastic behavior: application under cyclic shear loading. Journal of Adhesion Science and Technology, 2016, 30 (15), pp.1641-1661. 10.1080/01694243.2016.1157431 . hal-01701247

HAL Id: hal-01701247

https://hal-ensta-bretagne.archives-ouvertes.fr/hal-01701247

Submitted on 20 Sep 2021

HAL is a multi-disciplinary open access archive for the deposit and dissemination of scientific research documents, whether they are published or not. The documents may come from teaching and research institutions in France or abroad, or from public or private research centers.
L'archive ouverte pluridisciplinaire HAL, est destinée au dépôt et à la diffusion de documents scientifiques de niveau recherche, publiés ou non, émanant des établissements d'enseignement et de recherche français ou étrangers, des laboratoires publics ou privés.

\section{(c)(1)}

Distributed under a Creative Commons Attribution| 4.0 International License 


\title{
A fatigue life prediction method of adhesively bonded joints based on visco-elastic and visco-plastic behavior: application under cyclic shear loading
}

\author{
Pierre Bidaud ${ }^{a}$, Romain Créac'hcadec ${ }^{a}$, Pierre Jousset ${ }^{b}$ and David Thévenet ${ }^{a}$ \\ aLBMS, ENSTA Bretagne, 2 rue François Verny, 29806 Brest Cedex 9, France; bIWK, HSR, Oberseestrasse 10, 8640 \\ Rapperswil, Switzerland
}

\begin{abstract}
To perform an evaluation of the abilities of a bonded structure to endure repetitive loadings, characterizations of structural adhesive joints mechanical behavior are key objectives. The aim of this study is to describe the phenomena occurring in the bonded joint until the appearance of a macroscopic crack. Using lap-shear type specimens, associated with stress concentrations, crack initiation generally appears early at the edge of the adhesive joint, which makes it difficult to identify the crack initiation phase. To characterize more properly the crack initiation phase, bonded joints designed to limit stress concentrations allowed the accurate characterization of the mechanical phenomena occurring in a polyurethane structural ductile adhesive. Then, based on the experimental response of the bonded assembly to creep recovery tests, a visco-elastic visco-plastic behavior law is defined for the adhesive joint mechanical behavior. In the following, details of such a model able to take into account the hydrostatic sensitivity with a non-associated formalism are given. The numerical work performed here relies on the identification of the material parameters of the behavior law using creep-recovery tests to model the cyclic behavior of bonded structures. Then, experimental results under fatigue loading are presented and compared to numerical simulations. Finally, using a strain-based criterion for the definition of crack initiations, predictions of fatigue lifetime are performed for specimens under shear loadings. The quality of the results obtained underlines that an accurate description of viscous mechanisms in the adhesive layer allows describing efficiently the mechanical behavior of bonded joints under cyclic loading.
\end{abstract}

\section{KEYWORDS}

Adhesive; polymeric materials; behavior law; viscous deformation; Arcan device; cyclic behavior; fatigue

\section{Introduction}

Fatigue involves the failure of material under cyclic loading. In fatigue tests, the maximal loading considered can be significantly lower than that required to cause failure in a monotonic test. Considering the fact that in structures, compared to other joining methods, 
adhesive bonding permits to reduce stress concentrations, adhesive joints have potentially good fatigue strength. Nevertheless, adhesive joints are susceptible to accelerate fatigue failure due to viscous mechanical phenomena occurring in creep.

Evaluating fatigue performances of bonded structures, the total life method uses several standards: EN ISO 9664:1995 and ASTM D3166-99.[1] This type of specimen is known to introduce important stress concentrations. [2] Therefore, in testing these samples in fatigue, the crack generally appears early at the edge of the adhesive joint, and the onset of cracking can be easily registered.[3,4] Based on these observations, fracture mechanics is mostly considered, assuming crack initiation as a phenomenon occurring during the early stage of the fatigue cycling.[4] The important limitation of the design methods based on fracture mechanics is the hypothesis of a pre-cracked sample and the initiation phase is not accounted for.

In the model of bonded joints, the damage mechanics approach allows the consideration of a progressive degradation and failure of the adhesive representing both initiation and propagation phases at a microscopic scale. Generally, the introduction of a damage variable $D$ is required: initially equal to 0 (for an undamaged material), the variable evolved following fatigue damage equations to 1 for a fully damaged material.[5] The damage mechanics approaches are particularly suitable to Finite-Element (FE) applications to degrade the properties of the elements [6] and can include a time dependency of the behavior [7] which can be related to creep phenomena.

Creep deformations are time-dependent deformations which can occur in materials such as polymeric adhesives and may be considered as a key weakness for polymeric materials such as adhesive joints.[8] Evidences of creep influence on fatigue testing can be observed and application of standard fracture mechanics can significantly over predict the fatigue life if there is significant accumulated creep. $[9,10]$

As defined by [11] for vibro-creep tests, the mean cumulative displacement along a cyclic test can be viewed as a creep-fatigue interaction. This assumption is based on the empirical observation that failure of polymers due to dynamic fatigue greatly depends on their creep characteristics. Nevertheless, aside tests performed on adhesive film samples,[12] the notion of ratcheting effect in adhesive bonding remains confidential. Indeed, more generally, since the initiation phase seems to end early in bonded joints with the apparition of cracks at the edges of the overlap, fracture mechanics are considered to have the major role in the fatigue behavior for this testing method. The stress analyst's methods as important aspects in the initiation such as creep and damage effects were just sidelined in most studies. As an example, in a work performed on structural adhesives, Crocombe [13] concluded on a relatively unimportant effect of the frequency on the fatigue behavior. Nevertheless, when fatigue of adhesively bonded structures is approached with fatigue crack growth tests, such as DCB (Double Cantilever Beam) specimens, a greater number of studies exist, for the most leaded by Crocombe and co-workers.[10,14,15]

Yet despite this early assumption, the effect of viscosity in the adhesives behavior has been clearly highlighted in studies, by performing creep tests and tests under various loading rates. $[16,17]$ Thus, creep effects can be assumed to be significant in the lifetime of bonded structures $[18,19]$ and especially under fatigue loading through the influence of the temperature or the load frequency.[10,20] Therefore, an approach based on the numerous works performed on polymeric materials $[21,22]$ and composite materials $[23,24]$ needs to be adapted to the framework of the study of adhesively bonded structures. 
The aim of this study is to manage an approach based on a creep-fatigue coupling; evidences of the viscous phenomena occurring in the adhesive bond line have to be experimentally underlined. An important aspect to justify a creep-fatigue approach is the observation of a cumulative strain in bonded samples under load controlled cyclic loadings. A key step of this work is to develop a numerical description of the mechanical behavior of the structural adhesive studied based on an accurate experimental description of the necessary mechanical components. In this study, the experimental campaign presented is grounded on the use of a modified Arcan device using bonded specimen with low-edge effects (maximal stress state in the center of the adhesive).[25] This reduction of the edge effects is allowed by a modification of the initial Arcan samples and consists in the use of substrates geometry. In the first section of the work presented, using such a device, experimental results under monotonic and creep, cyclic loadings are shown for a two-component polyurethane SikaForce ${ }^{\varpi}-7817$ L60 MR adhesive. Then, a 3D material constitutive model is proposed for finite-element code implementation, allowing the analysis and the description of the mechanisms experimentally observed in creep in the adhesive. The second section of this document describes the assumptions made on the adhesive mechanical behavior, the components of the model and the inverse identification process of the material parameters. Then, using an adequate failure criterion based on the evolution of the strains in the adhesive layer, a prediction of fatigue life is performed in the third section.

\section{Experimental approach}

The aim of this section is to present the experimental campaign conducted on SikaForce -7817 L60MR [26] at room temperature. In the following, the experimental results are discussed in order to highlight the mechanical behavior of the adhesive under monotonic and cycliccreep loadings. Therefore, the experimental data have to be exhaustive and must include characterization tests in order to build a constitutive modeling for the adhesive behavior.

\subsection{Bonded specimens and bonding process}

In testing bonded specimens, uniformity of the stress and strain is not assured and edge effects can have a significant influence on the results obtained, especially for low-ductility adhesives.[25] To study accurately the behavior of an adhesive in an assembly under tensile/ compression-shear loads and to use a traditional tensile testing machine, a modified Arcan fixture was previously developed. The angle $\gamma$ defines the orientation between the loading direction and the mean plane of the adhesive (Figure 1(b)). In order to reduce edge effects, adherents include beaks with the specific geometry defined in Figure 1(a) on the edges of the bonded surface.

Since the positive influence of the beaks on the reduction of edge effects is ensured only for thin adhesive joints, $[27,28]$ the characterization tests were performed using a $0.2 \mathrm{~mm}$ adhesive joint thickness with bonding specimens including beaks. The different results presented in the following were obtained using a two components polyurethane structural adhesive SikaForce ${ }^{\oplus}-7817$ L60 MR (Table 1) and aluminum alloy substrates (2017). The bonded surfaces were sandpapered down, acetone degreased, and warmed with dry air. Finally, an alcohol solution containing a bond activating substance (Sika ${ }^{\varpi}$ Aktivator-205) is applied on each substrate. All the results presented in this paper were obtained with an 
(a)

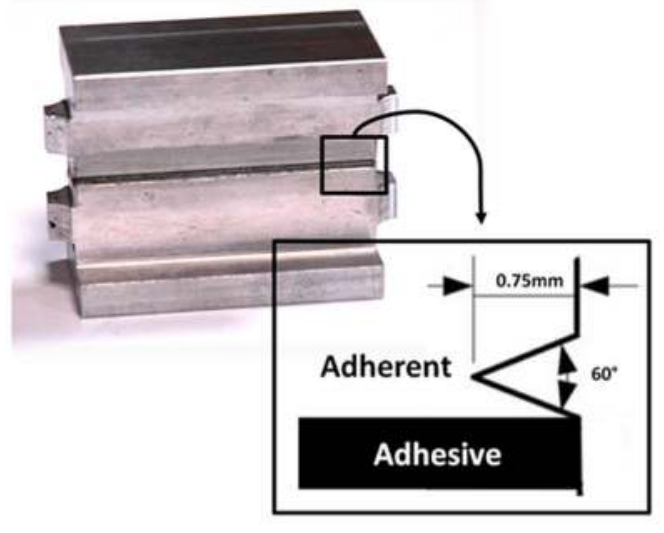

(b)

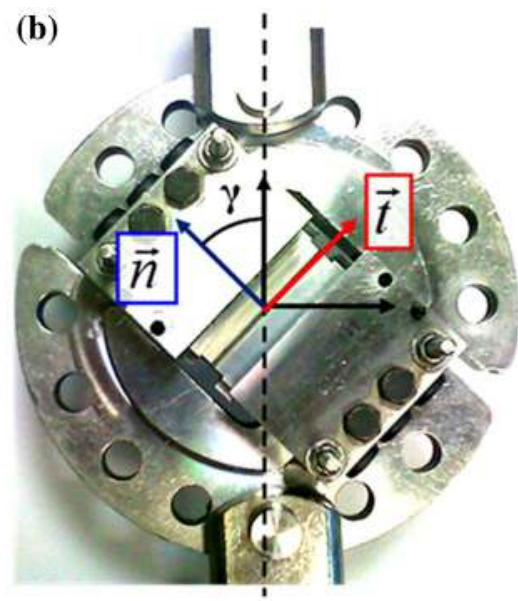

Figure 1. Bonded specimens: after the bonding procedure (a), and before the mechanical tests (b).

Table 1. Mechanical properties - SikaForce ${ }^{\circledR}$-7817 L60 MR.[26]

\begin{tabular}{lc}
\hline Properties & SikaForce ${ }^{\circledR} 7817$ L60MR \\
\hline Shore D hardness (DIN 53505) & $70\left(23^{\circ} \mathrm{C} / 50 \%\right.$ r.h. $)$ \\
E-modulus (ISO 527) & $2000 \mathrm{MPa}$ \\
Elongation at break (ISO 527) & $2.5 \%$ \\
Tensile strength (ISO 527) & $30 \mathrm{MPa}$ \\
Tensile lap-shear strength (ISO 4587) & $20 \mathrm{MPa}$ \\
Glass transition temperature (ISO11357-2) & $50^{\circ} \mathrm{C}$ \\
\hline
\end{tabular}

area of the bonded section of $475 \mathrm{~mm}^{2}$. Furthermore, advised by the formulator of this adhesive $\left(\mathrm{Sika}^{\circledast}\right)$, the bonding process is based on a thermal curing including three days at $60{ }^{\circ} \mathrm{C}$ preceded by one day at room temperature and after this curing, the samples are maintained at room temperature for two days before the experimental tests. This bonding process permits to have reliable experimental results for the mechanical tests performed due to their reproducibility.[29]

In the following, FT represents the applied load in the tangential direction of the bonded surface and $F N$ represents the applied load in the normal direction. The load components measured during the tests are from the testing machine load cell. In order to load the bonded joint in the 'normal stress-shear stress' plane, a modified Arcan device, allowing different load ratios FN/FT is used (Figure 1(b)). These ratios are applied, changing the angle $\gamma$ between the loading direction imposed by the testing machine and the normal to the bonded surface. The device allows this angle $\gamma$ to be varied in the range from $0^{\circ}$ to $135^{\circ}: \gamma=0^{\circ}$ corresponding to a tensile test, $\gamma=90^{\circ}$ corresponding to a shear test, and mixed tensile-shear $\left(\gamma=45^{\circ}\right)$ and compression-shear $\left(\gamma=135^{\circ}\right)$ tests can be obtained with intermediate positions. As for loading, following the same naming method, $D T$ and $D N$ are the relative displacement in the tangential and the normal direction of two markers placed on the substrates on both part of the adhesive at a distance of $1 \mathrm{~mm}$ from the edge of the adhesive joint. These displacements are tracked using an optical non-contact extensometer by Digital Image Correlation (DIC). 

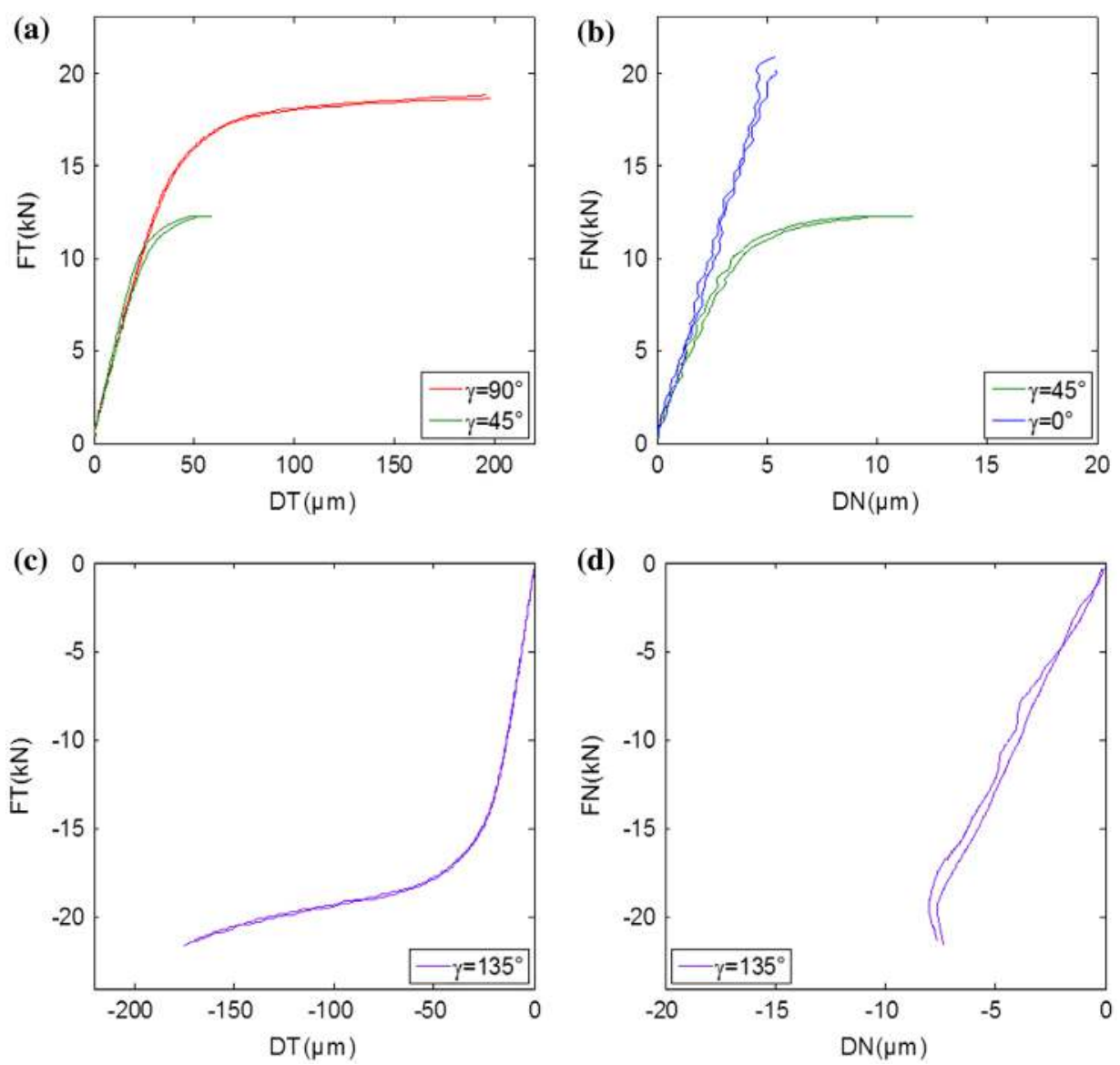

Figure 2. Experimental monotone results obtained for the SikaForce ${ }^{\oplus}-7817$ L60MR: under different load angles $\left(\gamma=0^{\circ} ; \gamma=45^{\circ} ; \gamma=90^{\circ} ; \gamma=135^{\circ}\right)$ in the normal direction (b and d) and in the tangential direction (a and $c$ ).

\subsection{Test campaign for the characterization}

\subsubsection{Monotonic tests}

The approach proposed in this work focus on the viscous aspects of the mechanical behavior. The choice of a loading rate range is thus important. Concerning recent wind-turbine designs with large rotor blades, the rotation speeds of the blades are below a value of $1 \mathrm{~Hz}$. Therefore, in this study concerning the cyclic behavior, assuming the fact that for windblade, the cyclic loadings are mainly due to its rotation, the experimental tests were performed on a base loading rate of $2 \mathrm{kN} / \mathrm{s}$. It will be shown in the last section of this paper that a $2 \mathrm{kN} / \mathrm{s}$ loading rate implies load frequencies consistent with these applications. Tests were performed in laboratory air and at room temperature.

Constant loading rate monotonic tests at $2 \mathrm{kN} / \mathrm{s}$ were performed on the SikaForce -7817 L60MR structural adhesive. Figure 2(a) shows the results obtained considering shear loading $\left(\gamma=90^{\circ}\right)$, tensile loading $\left(\gamma=0^{\circ}\right)$, tensile-shear loading $\left(\gamma=45^{\circ}\right)$, and compression-shear loading $\left(\gamma=135^{\circ}\right)$. The results are plotted in the tangential direction and normal direction Figure 2(c) and (d). In the tangential direction, concerning test performed under shear 
loading, a significant non-linear behavior was observed with a maximal displacement higher than $200 \mu \mathrm{m}$ (almost equivalent to the joint thickness).

For the tensile tests, a quasi linear shape is obtained for the FN-DN curves (Figure 2(b)). Nevertheless, in mixed tensile-shear loading, a non-linear part can be observed Figure 2(a) and (b). For a same shape of bonded specimen, the load at failure is substantially higher in compression shear than in tensile shear and tends to prove that the behavior of the structural adhesive considered may strongly be influenced by the hydrostatic stress.

\subsubsection{Creep-recovery test}

Creep-recovery tests are convenient for studying viscous effects since for a same specimen, several loading levels were played followed by a recovery part. Figure 3 displays the tangential displacement $(D T)$ during the cyclic creep-recovery test under shear loading.

The shape of the DT-Time curve for these tests allowed splitting viscosity in reversible and non-reversible phenomena:

- At low loads $(4,6 \mathrm{kN})$, creep occurred but the tangential displacement was fully recovered after the recovery time 1800s. The time-dependent effects were considered as visco-elastic;

- At the next higher loads $(8,10,12 \mathrm{kN})$, recovery was not completed and a residual tangential displacement was measured after the recovery step. The time-dependent residual displacement may be considered as a sign of plasticity. After this time period of $1800 \mathrm{~s}$, the residual displacement observed was assumed to be the evidence of a plastic flow.

In the tensile direction (Figure 3(d)), even if (according to the monotonic tests) the adhesive seemed to have an elastic brittle behavior, non-reversible strains were measured on the high levels of creep-recovery tests underlined by the same time dependency.

\section{Numerical approach}

The purpose of this section is to develop the constitutive equations in order to describe the mechanical behavior of the adhesively bonded joint under shear loading. The experimental study of the SikaForce -7817 L60MR, analyzed in the experimental study, was undertaken to develop the model constitutive elements.

\subsection{Modeling the viscous behavior}

As part of the definition of a phenomenological model, the experimental results in shear revealed important aspects of the bonded joint behavior. The model developed for the adhesive behavior must describe several mechanical features:

- A time-dependent and non-linear behavior implying viscosity on both short- and long-time scales;

- At high-load values, a plastic flow appears revealed by residual tangential displacements;

- The plastic flow is loading rate dependent.

Therefore, previous studies have shown that a model divided into two parts delimited by a threshold gives a good description for this mechanical behavior.[29] For load values 

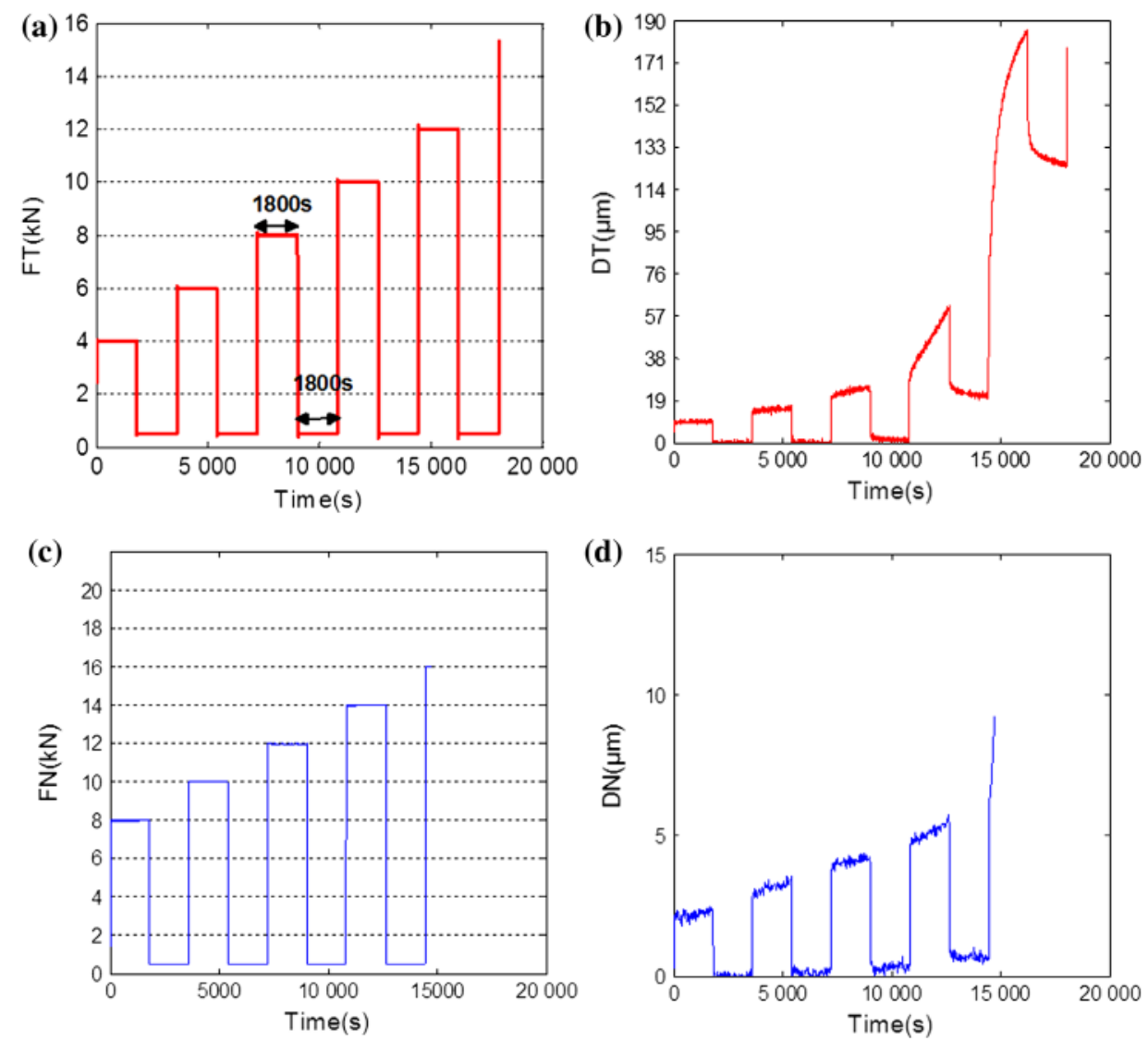

Figure 3. Cyclic tensile shear creep/recovery test: FT vs. Time (a) DN vs. Time and (b).

lower than the yield stress $R_{0}$, all strains are reversible. When load values are higher than this threshold, a visco-plastic flow appears.

For the 3D definition of the material behavior, a strain rate definition is used. In the following, as presented in Figure 4, the additive strain rate decomposition is assumed:

$$
\underline{\dot{\varepsilon}}=\dot{\dot{\varepsilon}}_{e l}+\dot{\dot{\varepsilon}}_{v 1}+\dot{\varepsilon}_{v 2}+\dot{\varepsilon}_{v p}
$$

The Hooke law permits to define the stress state:

$$
\dot{\underline{\sigma}}=\underline{\underline{C}}_{e}: \underline{\dot{\varepsilon}}_{e l}
$$

For the visco-elasticity, the stress state is calculated with the following equations:

$$
\begin{aligned}
& \dot{\dot{\varepsilon}}_{v 1}=\frac{1}{\tau_{1}}\left(\underline{\underline{S}}_{v 1}: \underline{\sigma}-\underline{\dot{\varepsilon}}_{v 1}\right) \\
& \dot{\underline{\varepsilon}}_{v 2}=\frac{1}{\tau_{2}}\left(\underline{S}_{v 2}: \underline{\sigma}-\dot{\underline{\varepsilon}}_{v 2}\right)
\end{aligned}
$$




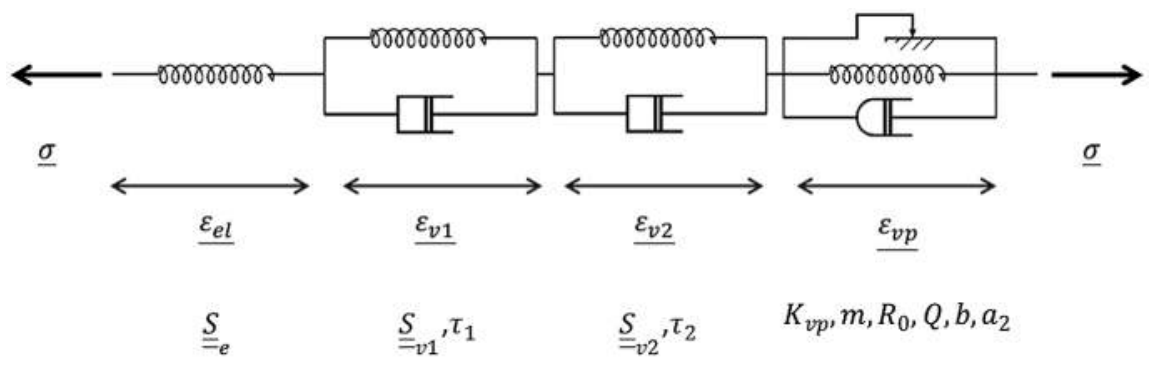

Figure 4. Formulation of the phenomenological model.

where $\underline{\underline{S}}_{v 1}$ and $\underline{\underline{S}}_{v 2}$ are the isotropic compliance tensors for the visco-elasticity and $\tau_{1}, \tau_{2}$ define the characteristic creep times for $\underline{\varepsilon}_{v 1}$ and $\underline{\varepsilon}_{v 2}$.

Concerning the formulation chosen for the plastic phenomena, if the hydrostatic pressure effect is neglected, the visco-plasticity may considerably be underestimated since the loading levels did not validate the von Mises yield criterion. Therefore, the yield function $f$ and the flow function $g$ were written with a dependency to the hydrostatic stress in order to translate the observations performed on the experimental monotonic tests with the different traction-shear ratios.

As a first approach, the yield surface for the visco-plasticity is based on a linear DruckerPrager formulation. The yield function is defined with the following equation:

$$
f(\sigma, p)=2 J+b I_{1}-R_{F}(p)
$$

with,

$$
\left\{\begin{array}{l}
J=\sqrt{3 J_{2}} \\
J_{2}=1 / 2(\underline{S}: \underline{S}) \\
\underline{S}=\underline{\sigma}-(1 / 3) \operatorname{Tr}(\underline{\sigma}) \underline{I d} \\
I_{1}=\operatorname{Tr}(\underline{\sigma})
\end{array}\right.
$$

where $b$ is a material constant, $J$ is the equivalent von Mises stress, $I_{1}$ is the hydrostatic pressure and the function $R_{F}$ defines the hardening rule.

For the hardening rule, a linear isotropic definition is used, so that the function $R_{F}$ is written:

$$
R_{F}(p)=R_{0}+Q p
$$

where $R_{0}$ is the initial yield stress and $Q$ a material parameter defining the linear hardening and $p$ is the plastic multiplier. When the yield criterion is reached, the irreversible strain rate defined by $\dot{\varepsilon}_{v p}$ occurs and is generated by the following equation:

$$
\underline{\dot{\varepsilon}}_{v p}=\left\langle\frac{f}{K_{v p}}\right\rangle^{m} \underline{n}
$$




$$
\underline{\dot{\varepsilon}}_{v p}=\dot{p} \underline{n}
$$

where $\left(K_{v p}, m\right)$ are material constants. $n$ represents the direction for the visco-plastic flow and depends on the flow function $g$.

$$
\underline{n}=\frac{\mathrm{d} g}{\mathrm{~d} \underline{\sigma}}
$$

with, $g(\sigma, p)=J+a_{2} I_{1}^{2}-R(p)$

Thus, the expression of $n$ :

$$
\underline{n}=3 / 2 \frac{S}{J}+2 a_{2} I_{1} \underline{I d}
$$

The equations developed in this 3D definition of a visco-elastic visco-plastic model are grounded on 14 material parameters:

- The Young modulus $E$ and the Poisson's ratio $v$ permit to define the linear elastic stiffness $\underline{\underline{C}}$;

- $\left(E_{1},{ }_{1}\right)$ and $\left(E_{2},{ }_{2}\right)$ are introduced as the parameters of the compliances $\underline{S}_{v 1}$ and $\underline{S}_{v 2}$. Added to $\tau_{1}$ and $\tau_{2}$ which are the characteristic creep times, they constitute the necessary parameters to define the visco-elastic behavior. As a first approach to define the visco-elastic strains, two mechanisms were chosen in order to explain both loading rate and creep effects. The first mechanism with the shorter characteristic creep time $\left(\tau_{1}<10 s\right)$ aims the definition of the loading rates influence, while the second mechanism aims the definition of creep effect.

- Finally, $K_{v p}, m, R_{0}$ and $Q$ associated to $b$ and $a_{2}$ are the material constants driving the visco-plastic flow and the flow direction.

In order to model the bonding assemblies behavior, the constitutive equations were implemented in the Abaqus ${ }^{\circledR} \mathrm{FE}$ code with a user material subroutine (UMAT).

\subsection{Inverse identification}

The identification of the model using the modified Arcan test is based on an inverse process. The inverse identification method of the material parameters takes into account the non-uniform stress distribution along the adhesive overlap.[29] This numerical method couples the numerical results, given by the Abaqus ${ }^{\mathrm{mt}} \mathrm{FE}$ code, and the optimization software Python ${ }^{\text {tw }}$ considering the non-linear optimization library NLOPT. Concerning the optimization works performed in this thesis, the algorithm used was based on an implementation of a globally convergent method of moving asymptotes (MMA) implementation. This algorithm was developed for gradient-based local optimization, including inequality constraints. The 'globally convergent' term does not mean that the algorithm systematically converges to the global minimum. The only convergence guaranteed is to some local minimum depending on: the starting point, the constraints and the gradient definition. 


\subsubsection{Finite element model (3D)}

With the development of a 3D model implemented in a FE analysis, all the particular geometric specificities of the modified Arcan test can now be defined for the identification of the material parameters. However, taking the width of the specimen into account will lead to a multiplication of the elements within the model and inescapably a growth in the computational time. Therefore, the convergence of the numerical tangential and normal responses $\left(\gamma=45^{\circ}\right)$ was investigated for two FE models:

- A first 3D model of the Arcan specimen includes the particular shape of the corners and the geometrical widthwise specificities and a meshing refinement was performed in the concerned areas (Figure 5(a)). Nevertheless, the symmetries in the model permitted to divide the number of elements by two;

- A second 3D model (Figure 5(b)) was created with a single element in the width (following the $\vec{y}$ direction) assuming the assumption of a low influence of the geometry widthwise.

For a given set of material parameters, the simulations were performed using linear hexadral elements with reduced integration (C3D8R). The loading was applied to driving points (points 1 and 2 on Figure 5(a) and (b)) cinematically coupled to the upper surfaces of the substrates and the loading value was adapted to the bonded surface represented on each model. As shown in Figure 5(c) and (d), the numerical response of a monotonic loading gave similar results for these two models. Therefore, in order to reduce the computational time, the 3D model of the modified Arcan bonded specimen with a unique element in the width will be adopted for the rest of this study.

\subsubsection{Identification strategy}

The choice of a step-by-step identification is necessary in order to reduce the computational time for the convergence to the solution. The partition of the material parameters to identify at each step is the following:

- Step 1, concerns the identification of the elastic behavior: the parameters of the $\underline{C}$ tensor are defined using a linear FE analysis of the monotonic shear behavior (Arcan modified tests with $\left.\gamma=90^{\circ}\right)$ and the monotonic tensile behavior $\left(\gamma=0^{\circ}\right)$;

- Step 2, concerns the identification of the visco-elastic behavior under shear loading. Two optimization loops are used on the shear creep results for the 4 and $6 \mathrm{kN}$ load levels (Arcan modified tests with $\gamma=90^{\circ}$ ). The first optimization is run to define the characteristic creep times $\left(\tau_{1}\right.$ and $\left.\tau_{2}\right)$ on the normalized value of the equivalent visco-elastic displacement $\left(D T_{\text {VEnorm }}\right)$. Then, the second optimization is made on the visco-elastic displacement measured (the non-normalized value $D T_{V E}$ ) for these two load levels in order to determine $\underline{\underline{S}}_{v 1}=\underline{C}_{v 1}^{-1}$ and $\underline{\underline{S}}_{v 2}=\underline{C}_{v 2}^{-1}$. Concerning the reversible strains $\left(\underline{\varepsilon}_{r v v}=\underline{\varepsilon}_{e 1}+\underline{\varepsilon}_{v 1}+\underline{\varepsilon}_{v 2}\right)$ an assumption of isotropic behavior is made. In this study, the Poisson's ratios for the elastic strain $\left(\underline{\varepsilon}_{e l}\right)$ and visco-elastic strains $\left(\underline{\varepsilon}_{v 1}\right.$ and $\left.\underline{\varepsilon}_{v 2}\right)$ are considered to be the same. Hence, no results of Arcan under tension are needed to complete this step;

- Step 3, concerns the identification of the visco-plastic behavior in the shear direction. With the experimental response under shear cyclic creep, the following material constants are defined: the initial yield stress $R_{0}$, the hardening parameter $Q$ and the parameter of the plastic flow intensity $K_{v p}$ and $m$. As the modified Arcan test with the 


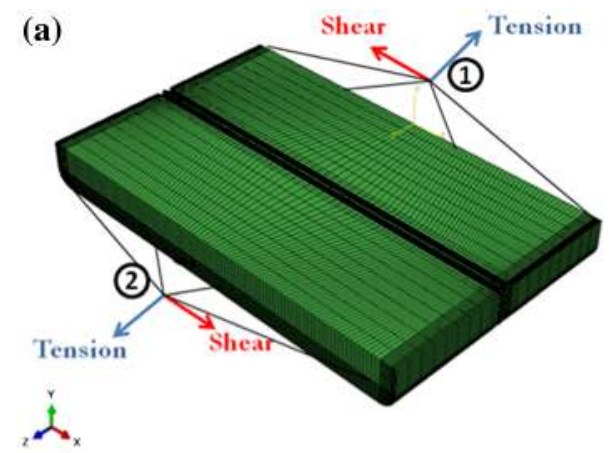

Adhesive Joint: $24 \times 130$ elements

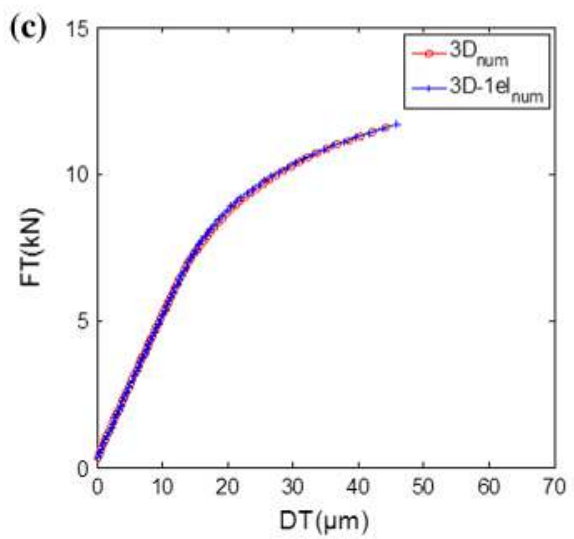

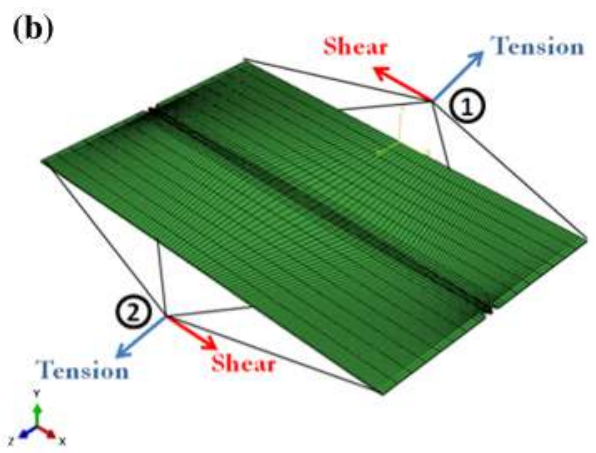

Adhesive Joint: 1x130 elements

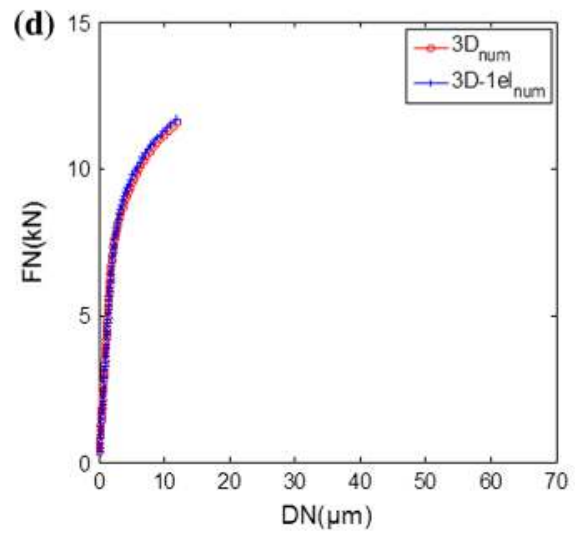

Figure 5. Comparison between the numerical response of a 3D complete model (a) and a model with a single element in the width (b): monotonic tangential (c) and normal (d) response to a modified Arcan test $\left(\gamma=45^{\circ}\right)$.

$\gamma=90^{\circ}$ configuration gives a quasi-pure shear stress state, the other parameters of the yield function will not have an important influence on the mechanical behavior. Indeed, FE analysis shows that the hydrostatic stress component is negligible within the bonded layer in a shear configuration.[30] Considering the definition of the flow function defined previously, this leads to a behavior independent of $b$ and $a_{2}$;

- Step 4, concerns the identification of the hydrostatic stress influence. Therefore, experimental results with ratios including tension $\left(\gamma=0^{\circ}\right.$ or $\left.\gamma=45^{\circ}\right)$ are needed. The remaining yield function parameter $b$ and flow rule parameter $a_{2}$ are determined using an inverse identification based on the cyclic creep/recovery test under tensile-shear loading $\left(\gamma=45^{\circ}\right)$.

At the end of the identification strategy, an 'optimal' parameter set is obtained for the SikaForce 7817 L60MR. The results presented in Figure 6 show the abilities of the constitutive visco-elastic visco-plastic equations with a non-associated and hydrostatic stress-dependent model on creep-recovery tests. The numerical response for loading and unloading with the parameters identified provides encouraging results for shear, tensile-shear and tensile creep-recovery loadings. The viscous behavior is significantly more important in 

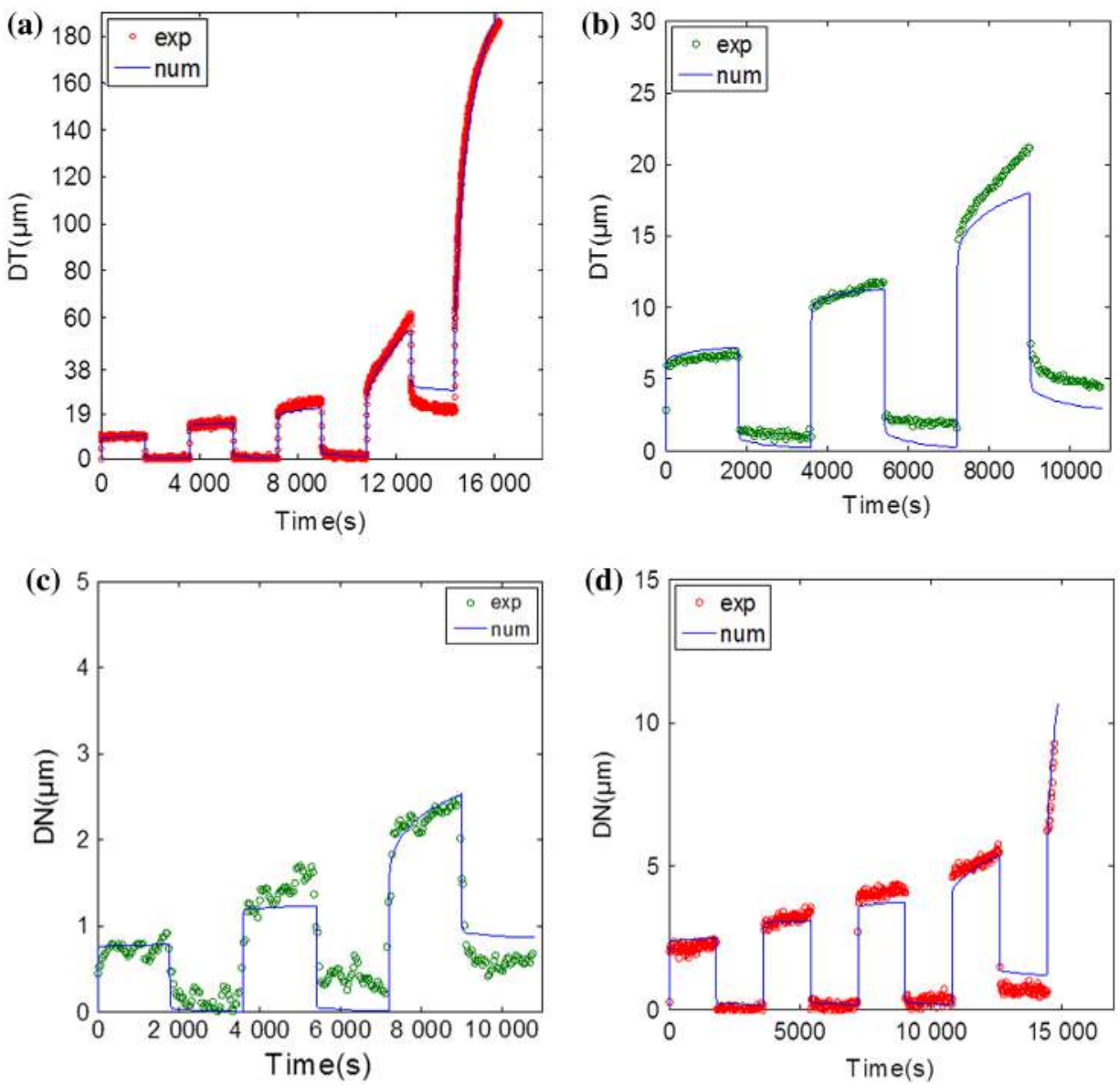

Figure 6. Identification of the visco-elastic visco-plastic behavior on the shear $\left(\gamma=90^{\circ}\right)$ creep-recovery test (a) and the tensile-shear $\left(\gamma=45^{\circ}\right)$ creep-recovery test (b) and (c). Validation of the behavior from the tensile $\left(\gamma=0^{\circ}\right)$ creep-recovery test (d).

shear than for the response obtained under tension and tension-shear. The constitutive model developed is able to describe this difference.

\subsubsection{Interest of the formalism}

The interest of the model definition proposed (non-associated formalism, taking into account the hydrostatic stress influence) is justified in Figure 7 regarding the response under tensile-shear loading $\left(\gamma=45^{\circ}\right)$. The definition of a new parameter set considering $a_{2}=b=0$ permits to neglect the effect of the hydrostatic stress. Associated formalism permits to only use the yield function in the flow definition. The response of an associated formalism is thus investigated by removing the $g$ function in the model definition and replacing it by the yield function $f$ :

$$
\dot{\varepsilon}_{v p}=\dot{p} \frac{\mathrm{d} f}{\mathrm{~d} \underline{\sigma}}
$$



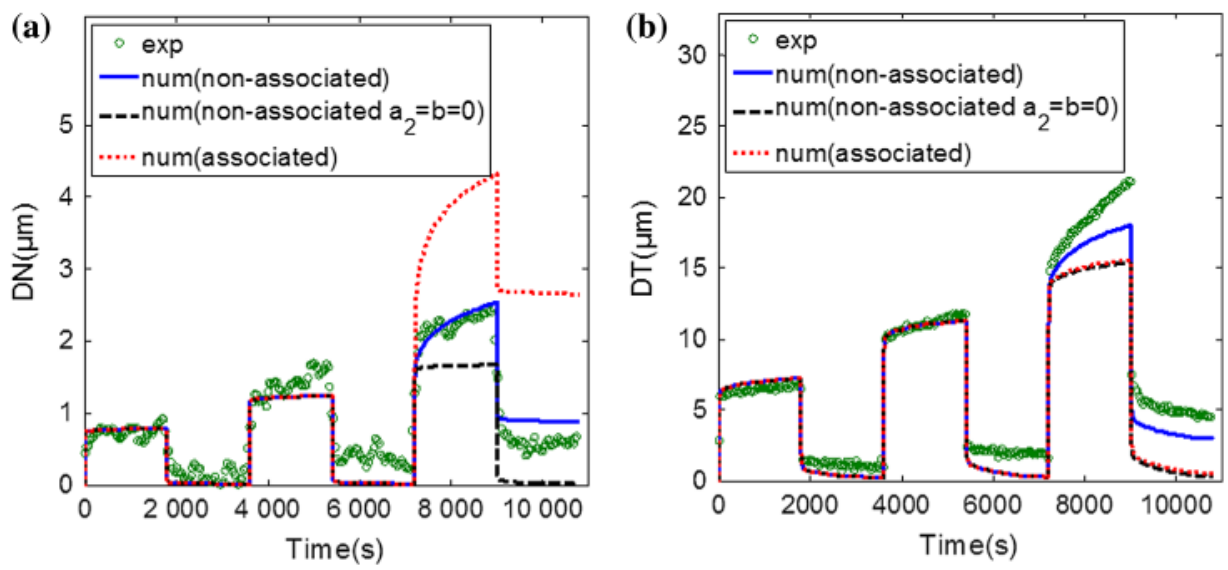

Figure 7. Interest of a non-associated formalism with influence of the hydrostatic stress: normal (a) and tangential response (b) to a cyclic creep tensile-shear test $\left(\gamma=45^{\circ}\right)$.

In that case, the yield criterion and the plastic flow are equivalent to a classical VonMises formulation and are incapable to take the influence of the hydrostatic pressure into account. A comparison between an associated and non-associated formalism is thus possible. Concerning the plotted results (Figure 7), parameters were not modified from the identification performed with the non-associated formalism. With this parameter set, the numerical response of an associated formalism clearly overestimates the plastic behavior in the tangential direction. On the contrary, the plastic flow in the normal direction was close to zero. Therefore, the use of a non-associate formalism with the definition of a different flow function permits to reduce the discrepancy observed in the plastic flow in both normal and tangential directions.

Since all the identification process has been made with creep/recovery experimental data implying long-term mechanisms, it may be relevant to have a view on the model response to short-term monotonic loadings. For a $2 \mathrm{kN} / \mathrm{s}$ loading rate, under tensile-shear loading $\left(\gamma=45^{\circ}\right)$ and tensile loading $\left(\gamma=0^{\circ}\right)$, the numerical responses of the non-associated hydrostatic stress-dependent model are presented in Figure 8(a)-(c). The model developed shows satisfactory results in both tangential and normal direction.

\subsection{Failure criterion}

Using a modified Arcan device, under shear loading, the displacement at failure from the comprehensive experimental database underlined a value close to the adhesive joint thickness. This result was acceptable for both monotonic and cyclic tests for a given loading rate of $2 \mathrm{kN} / \mathrm{s}$ (Figure 9(a)). Therefore, assuming that this observation is true, a failure strainbased criterion will be developed. In order to introduce a failure criterion, a User Output Variable (UVARM) called $C_{f}$ was created in the user material subroutine. This variable was calculated at each increment of the FE analysis and was defined by:

$$
C_{f}=\left(\varepsilon_{e q} / \varepsilon_{f_{e q}}\right)^{2}+\left(\varepsilon_{H} / \varepsilon_{f_{H}}\right)^{2}
$$



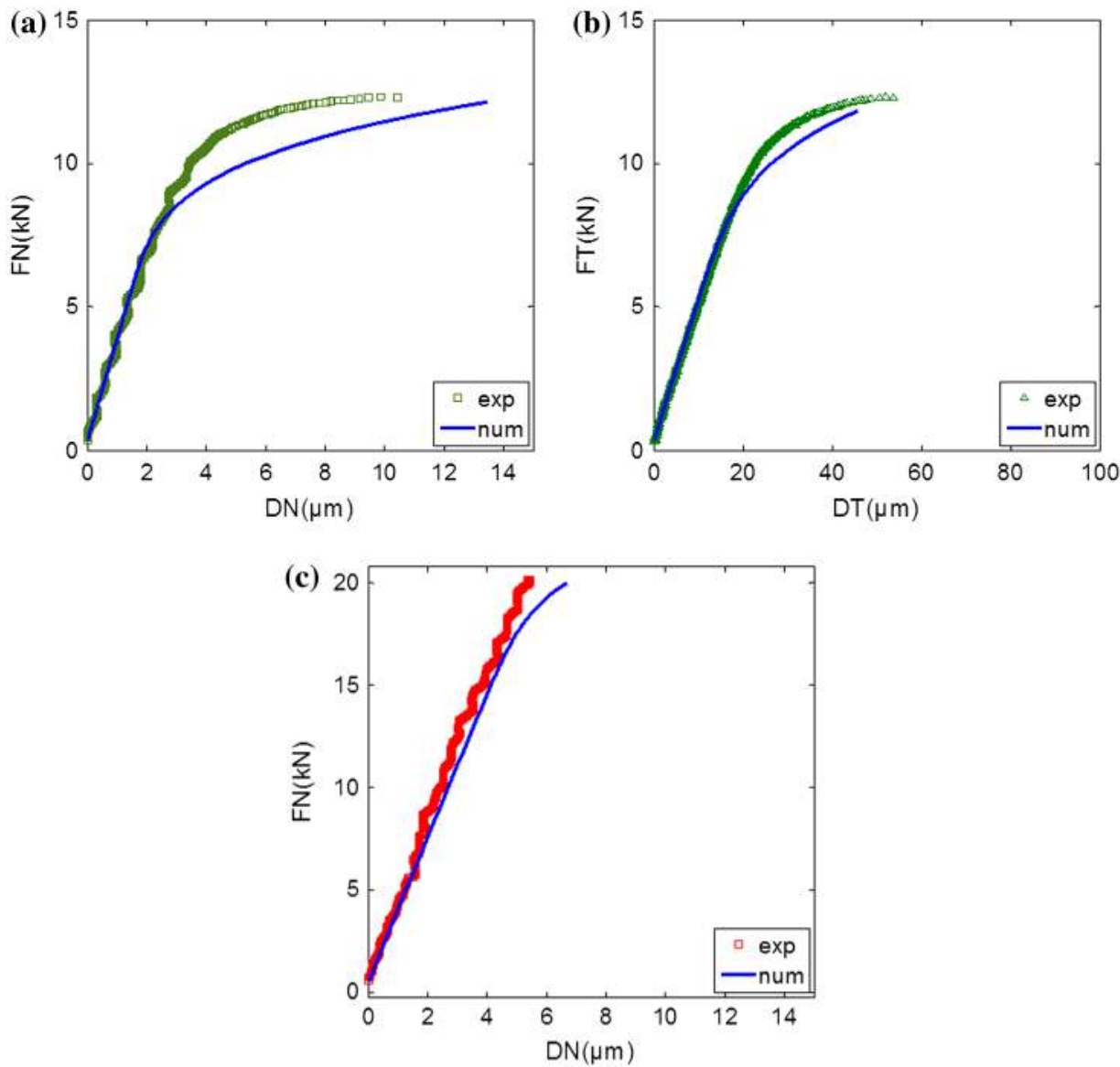

Figure 8. Numerical response under monotonic loadings: tensile-shear test $\left(\gamma=45^{\circ}\right)$ (a) and (b) and tensile test $\left(\gamma=0^{\circ}\right)$ (c).

with,

$$
\left\{\begin{array}{l}
\varepsilon_{e q}=\sqrt{2 / 3(\underline{D}: \underline{D})} \\
\underline{D}=\underline{\varepsilon}-(1 / 3) \operatorname{Tr}(\underline{\varepsilon}) I d \\
\varepsilon_{H}=1 / 3 \operatorname{Tr}(\underline{\varepsilon})
\end{array}\right.
$$

where $\varepsilon_{f_{e q}}, \varepsilon_{f_{H}}$ defined the equivalent and hydrostatic failure strains computed with the total strain tensor $\underline{\varepsilon}$. A failure within the adhesive is considered as soon as the variable $C_{f}$ has raised a value above or equal to 1 . Then, the criterion is considered to be reached and the numerical simulation is stopped by the subroutine.

The modified Arcan device under shear loading $\left(\gamma=90^{\circ}\right)$, for thin adhesive joints, is associated to a pure shear stress state with no stress concentrations.[31] Therefore, using the system of axis given in Figure 5(a), for bonded specimen under shear loading, the following assumption is thus made: 

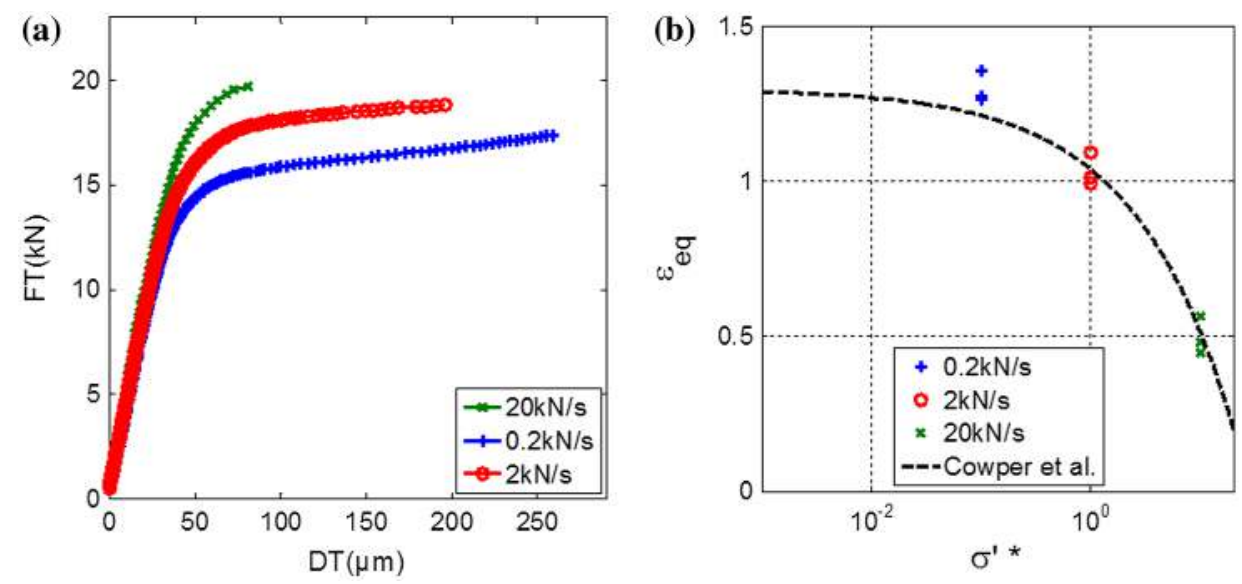

Figure 9. Identification of the Cowper et al. [32] criterion parameters (a) based on experimental failures observed under monotonic shear loadings (b).

$$
\left\{\begin{array}{l}
\varepsilon_{e q}=(2 / \sqrt{3}) \varepsilon_{13} \\
\varepsilon_{H}=0
\end{array}\right.
$$

Following the previous assumptions, the failure criterion (Equation (1.2)) may thus be expressed as follow:

$$
C_{f}=\left(\varepsilon_{e q} / \varepsilon_{f_{e q}}\right)^{2}
$$

Concerning results under shear loading, a dependency on the loading rate of the measured displacement at failure was observed on the monotonic behavior Figure 9(b). The criterion developed is based on the definition of the strain to fracture as a function of the strain rate.

Therefore, based on the works of Cowper et al.[32] a definition of the equivalent failure strain suitable to this application case could be expressed as follow:

$$
\varepsilon_{f_{e q}}=D_{1}^{*}\left(1-D_{2}^{*}\left(\dot{\sigma}^{*}\right)^{1 / D_{3}^{*}}\right)
$$

with,

$$
\sigma^{*}=\frac{\dot{\sigma}_{V M}}{\dot{\sigma}_{V M_{2 \mathrm{kN} / \mathrm{s}}}}
$$

In this last expression, a set of three material parameters are needed: $D_{1}^{*}, D_{2}^{*}$ and $D_{3}^{*}$. As the values of the failure strain were equivalent in cyclic and monotonic tests, the identification of the material parameters can be done on both. For this expression, the first parameter, $D_{1}^{*}$, could be seen as an initial mean value for the strain to failure $\varepsilon_{f_{e q}}$. Therefore, these parameters were defined equal to the mean equivalent failure strain measured for a $2 \mathrm{kN} / \mathrm{s}$ shear test. The remaining parameters, $D_{2}^{*}$ and $D_{3}^{*}$, were defined using the failure data of a second 


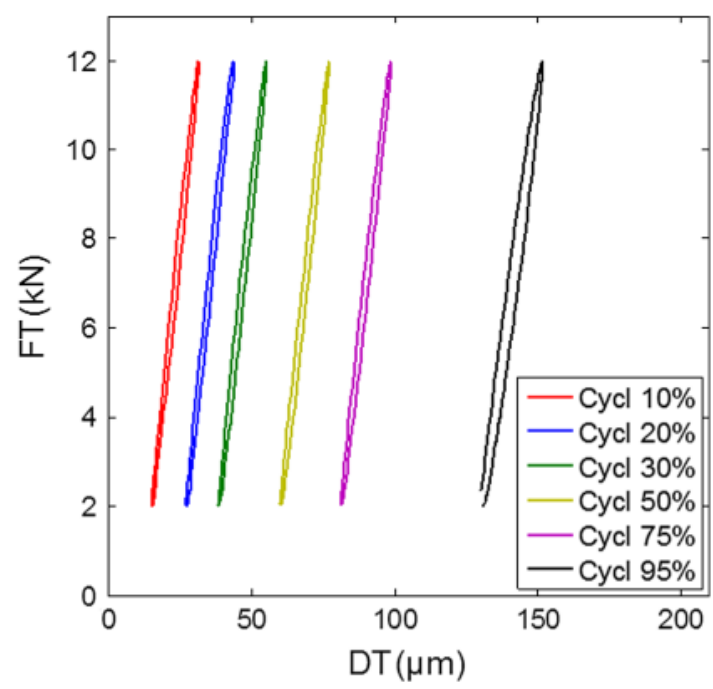

Figure 10. Evolution of the mechanical response under cyclic loadings (relative to the fatigue life): mechanical behavior in the range of the total tangential displacement.

loading rate. The identification of the material parameters was performed considering a mean value in the adhesive joint strain. In order to develop a more accurate definition of the parameters, an inverse identification should be developed.

The variable $C$ was computed at each integration points of the adhesive bond-line elements. Numerically, under monotonic shear loadings, the criterion was reached in the middle of the overlap. This result was consistent with the previous studies performed on the failure prediction based on a modified Arcan device.[33]

\section{Validation of the approach based on fatigue results}

The validation of the numerical model and failure prediction were performed on the longterm cyclic behavior. The fatigue cyclic tests were conducted at room temperature and for load ratios $R=F_{\min } / F_{\max }$ strictly positive. As the application of this study is the windmill industry, frequencies close to the speed of rotation of the wind blades were chosen for this experimental campaign: loading frequencies lower than $0.25 \mathrm{~Hz}$ except for two fatigue tests performed concerning the loading rate influence.

\subsection{Cyclic behavior predictions}

For cyclic tests with a non-zero mean stress, two phenomena can be observed depending on the material and on the loading conditions:

- A cyclic stabilization of the loops: the shape of the loops does not vary and the curve describes a stabilized hysteretic loop in the FT-DT plane;

- A progressive cumulative strain growth after each cycle during the test, Figure 10 presents few hysteretic loops drawn in the FT-DT plane at different steps of a test taken from 10 to $95 \%$ of the fatigue lifetime. The evolution of the mean displacement 
along the cycle can be linked to the viscous mechanisms occurring within the adhesive joint. This phenomenon experimentally observed for the specimens considered in this study is called ratcheting effect.

In the following, the abilities of the numerical model to retrieve the cyclic experimental response are based on the evolution of the ratcheting displacement plotted as a function of the number of cycles. The ratcheting effect was investigated with the mean value of the displacement along a cycle, and for a given number of cycles $n$, the ratcheting effect is defined with the evolution of the following function:

$$
D_{r}(n)=\frac{D_{\max }(n)+D_{\min }(n)}{2}
$$

where $D_{\max }$ defines the maximal value along the cycle, and $D_{\min }$ the minimal value and $D_{r}$ represents the 'ratcheting' displacement. $D T_{r}$ represents the tangential part and $D N_{r}$ the normal part of the displacement.

Table 2 lists the experimental tests performed under shear with the associated loading parameters. The trend, observed on the experimental campaign, seems to be well transcribed by the model. Figure 11(a) presents a numerical-experimental comparison on the influence of the mean load on the cyclic behavior for three different loading cases: $F T_{a}=2 \mathrm{kN} / F T_{m}=8$, 9 and $10 \mathrm{kN}$. As presented in Table 2, until the experimental test number 14, in order to avoid the effect of the loading rate parameter on the results, loading frequencies were adapted to have the same loading rate. The abilities shown by the simulation on the description of the long-term behavior permit to give a good evaluation of the cumulative displacement. The numerical simulation, performed with the lower load level $\left(F T_{m}=8 \mathrm{kN}\right)$, was manually stopped 'before' reaching the failure criterion as the computation time was considered as heavy.

The description of the loading rate influence by the numerical model is presented in Figure 11(b). With the viscous mechanical elements chosen for the modeling of the adhesive

Table 2. List of cyclic tests under shear loadings ( $\mathrm{s}=$ stopped).

\begin{tabular}{|c|c|c|c|c|c|}
\hline \multirow{2}{*}{$\begin{array}{l}\text { Load } \\
\text { Frequency }(\mathrm{Hz})\end{array}$} & \multirow[b]{2}{*}{$F T_{a}(\mathrm{kN})$} & \multirow[b]{2}{*}{$F T_{m}(\mathrm{kN})$} & \multirow{2}{*}{$\begin{array}{c}\text { Sample } \\
N^{\circ}\end{array}$} & \multicolumn{2}{|c|}{ Failure } \\
\hline & & & & $D T_{f}(\mu \mathrm{m})$ & $N_{f}$ (cycles) \\
\hline \multirow[t]{9}{*}{0.25} & 2 & 9 & 1 & 232 & 23,119 \\
\hline & & & 2 & 234 & 8893 \\
\hline & & & 3 & 200 & 82,215 \\
\hline & 2 & 10 & 4 & 231 & 888 \\
\hline & & & 5 & 229 & 1663 \\
\hline & & & 6 & 236 & 4321 \\
\hline & 2 & 8 & 7 & $158^{\mathrm{s}}$ & $100,000^{s}$ \\
\hline & & & 8 & $150^{5}$ & $100,000^{s}$ \\
\hline & & & 9 & 221 & 21,003 \\
\hline \multirow[t]{5}{*}{0.1} & 5 & 7 & 10 & 192 & 1,52 \\
\hline & & & 11 & 199 & 2471 \\
\hline & & & 12 & 170 & 1081 \\
\hline & & & 13 & 248 & 517 \\
\hline & & & 14 & 250 & 303 \\
\hline \multirow[t]{2}{*}{0.01} & & & 15 & 290 & 10 \\
\hline & & & 16 & 242 & 18 \\
\hline \multirow[t]{2}{*}{10} & & & 17 & 160 & 3147 \\
\hline & & & 18 & 185 & 925 \\
\hline
\end{tabular}



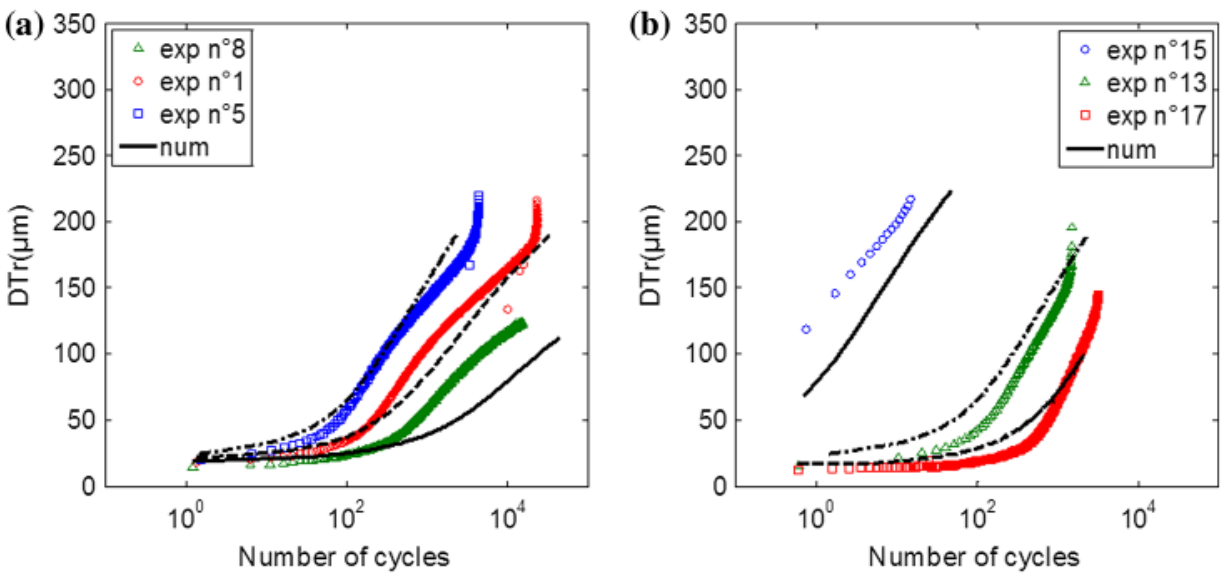

Figure 11. Experimental/numerical comparison of $D T_{r}$ until failure: influence of the mean load (a) and influence of the loading rate (b).

mechanical behavior, the influence of this parameter on the ratcheting effect can numerically be retrieved.

\subsection{Fatigue life predictions}

The FE analysis ensured a satisfying description of the ratcheting displacement $\left(D T_{r}\right)$ under fatigue loading for the underlined factors of influence: mean load, load amplitude, loading rate. Therefore, a numerical prediction of the fatigue life of modified Arcan specimens under shear loading was thus possible. As the load amplitude $F T_{a}$ did not involve substantial differences in the experimental and numerical fatigue lives, the results are plotted as a function of $F T_{\max }$.

Figure 12 presents the results of a numerical/experimental comparison concerning the influence of the loading rate on the fatigue life. In order to model the loading rate influence (or frequency influence) on $D T_{r}$, a relation can be developed: increasing the loading rate, the number of cycles to failure $N_{f}$ may grow proportionally. Nevertheless, the criterion developed and identified from monotonic tests was loading rate dependent and this criterion predicted lower displacements for the higher loading rates. Hence, concerning the influence of the loading rate, for the loading case $\left(F T_{a}=5 \mathrm{kN} / F T_{m}=7 \mathrm{kN}\right)$, the number of cycles until failure $N_{f}$ was also related to the cumulative tangential displacement at failure predicted by the Cowper et al. criterion. The numerical response on DT using the constitutive model, coupled with the criterion developed, permitted to perform a good prediction of the influence of the loading rate.

\section{Conclusion}

The approach of the adhesive joint mechanical behavior, proposed in this work, is based on the experimental response from creep-recovery tests and extended to the prediction of the cyclic behavior of $0.2 \mathrm{~mm}$ modified Arcan specimens. Experimental and numerical investigations were performed in order to take into account the influences of the mean stress and 

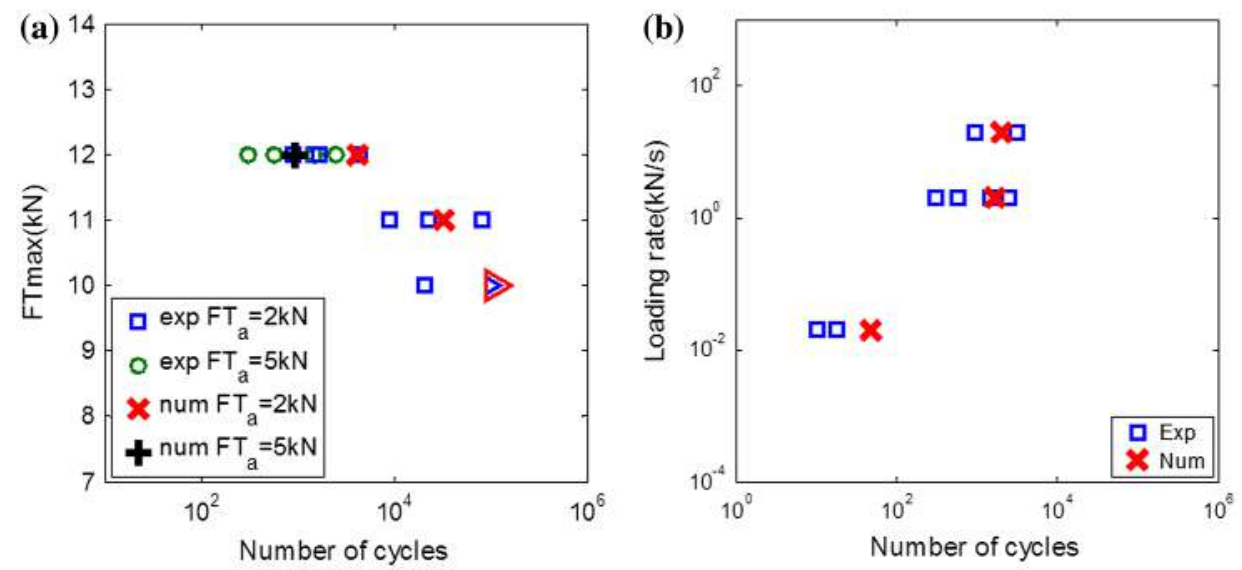

Figure 12. Experimental/numerical comparison of fatigue lifetime in $F T_{\max }$ scale (a) and influence of the loading rate for a given loading case $\left(F T_{a}=5 \mathrm{kN}, F T_{m}=7 \mathrm{kN}\right)(\mathrm{b})(\triangleright=$ stopped).

the stress amplitude and the effect of the frequency (loading rate) in the characterization of the fatigue behavior. To achieve this goal, the approach outlined in this project was to model the viscous behavior for the adhesive joint and to investigate the numerical response in term of cumulative displacement. Under cyclic shear loading, the mean cumulative displacement $\left(D T_{r}\right)$ numerical response correlated the experimental response measured. For a given loading rate, experimental results under shear loading revealed that the displacement at failure was reproducible for each $F T_{a} / F T_{m}$ couples tested.[29,34] Taking into account this interesting experimental observation, a strain-based failure criterion was developed in this study. Numerical prediction of the fatigue lifetime was thus performed for loading cases involving number of cycles to failure below $10^{5}$. Under shear loading and for the tested loading cases, experimental/numerical comparisons in terms of fatigue lifetime allowed us to show the relevancy of such an approach.

For the lower loading cases tested, even if a first estimation on the abilities of the numerical response can be developed, both simulation and experimental tests did not end by a failure scenario. Indeed, the strong assumptions made on a fatigue behavior neglecting the damage mechanics and the environmental aspect seems to show their limits on these loading cases which implies fatigue lifetime better than $10^{5}$ cycles. In order to validate the approach and to extend the scope of application of the predictive tool developed further experimental studies should be performed: cyclic tests on tensile, tensile-shear loadings and for greater fatigue lifetime. In order to reach this goal, a better comprehension of the micro-mechanisms involved in the degradation of the adhesive joint and the interfaces is a necessary step.

As first approach results were shown loadings in shear, tension and a single tension/ shear ratio. Further studies would include cyclic results under different tension/shear ratios, compression/shear. 


\section{Acknowledgments}

The authors would like to thank Sika Technology AG for financing and supporting this project and supplying the adhesive material, and the Brittany region for financing this work. The authors are grateful to S. Moyne from LBMS $\backslash$ ENSTA Bretagne for his help on all the numerical aspects and JY. Cognard from LBMS $\backslash E N S T A$ Bretagne for opening the way for the commencement of this work.

\section{Disclosure statement}

No potential conflict of interest was reported by the authors.

\section{References}

[1] Standard test method for fatigue properties of adhesives in shear by tension loading. D 9. ASTM D3166-99; 2012.

[2] Adams RD, Mallick V. A method for the stress analysis of lap joints. J. Adhes. 1992;38:199-217.

[3] Dessureault M, Spelt JK. Observation of fatigue crack initiation and propagation in an epoxy adhesive. Int. J. Adhes. Adhes. 1997;17:183-195.

[4] Shenoy V, Ashcroft IA, Critchlow GW, et al. An investigation into the crack initiation and propagation behaviour of bonded single-lap joints using backface strain. Int. J. Adhes. Adhes. 2009;29:361-371.

[5] Lemaitre J, Chaboche JL. Mechanics of solid materials. Cambridge: Cambridge University Press; 2000.

[6] Moroni F, Pirondi A. An investigation of fatigue failure prediction of adhesively bonded metal/ metal joints. Int. J. Adhes. Adhes. 2009;29:796-805.

[7] Shenoy V, Ashcroft I, Critchlow GW, et al. Unified methodology for the prediction of the fatigue behaviour of adhesively bonded joints. Int. J. Fatigue 2010;32:1278-1288.

[8] Geiss PL. Veirarbeitungskonzepte und belastungskriterien für Haftklebstoffe. Munich: University of Kaiserslautern Munich; 1998.

[9] Begley JA, Landes JD. Mechanics of crack growth. Proceedings of the Eighth National Symposium on Fracture Mechanics ASTM STP 590. 1976: 128-148.

[10] Al-Ghamdi AH, Ashcroft IA, Crocombe AD. Crack growth in adhesively bonded joints subjected to variable frequency fatigue loading. J. Adhes. 2003;79:1161-1182.

[11] Vinogradov AM, Jenkins CHM, Winter RM. Cyclic loading effects on durability of polymer systems. Long term durability of structural materials. University of California, Berkeley: Elsevier. 2001; 9, 159-170.

[12] Ma J, Gao H, Gao L, et al. Uniaxial ratcheting behavior of anisotropic conductive adhesive film at elevated temperature. Polym. Test. 2011;30:571-577.

[13] Crocombe AD, Richardson G. Assessing stress state and mean load effects on the fatigue response of adhesively bonded joints. Int. J. Adhes. Adhes. 1999;19:19-27.

[14] $\mathrm{Xu} \mathrm{X}$, Crocombe AD, Smith P. Fatigue behaviour of joints bonded with either filled, of filled and toughened, adhesive. Int. J. Fatigue 1994;16:496-477.

[15] Pirondi A, Nicoletto G. Fatigue crack growth in bonded DCB specimens. Eng. Fract. Mech. 2004;71:859-871.

[16] Cognard J-Y, Créaćhcadec R, Sohier L, et al. Analysis of the non linear behaviorof adhesive in bonded assemblies, comparison of TAST and Arcan test. Int. J. Adhes. Adhes. 2008;28:393-404.

[17] Dean G. Modeling non-linear creep behaviour of an epoxy adhesive. Int. J. Adhes. Adhes. 2006;27:636-646.

[18] Jeandrau J-P. Environmental and fatigue durability of structural adhesive-joints. Proceedings of the First International Conference on Structural Adhesive Bonding; 2011.

[19] Imanka M, Hamano T, Ashino R, et al. Fatigue damage evaluation of adhesively bonded butt joints with rubber modified epoxy adhesive. J. Adhes. Sci. Technol. 2003;17:981-994. 
[20] Bidaud P, Créac'hcadec R, Thévenet D, et al. Analysis of the cyclic behavior of an adhesive in an assembly under tensile-shear loading. Proceedings of the 9th European adhesion conference; 2012 .

[21] Launay A, Maitournam MH, Marco Y, et al. Cyclic behavior of short glass fibre reinforced polyamide: experimental study and constitutive equations. Int. J. Plast. 2011;27:1267-1293.

[22] Nguyen STT. Caractérisation expérimentale et modélisation thermomécanique de laccomodation cyclique du polyethylène. Ecole Nationale Supérieure de Mécanique et d'Aérotechnique. Chasseneuil du Poitou; 2013.

[23] Laurin F. Approche multiechelle des mécanismes de ruine progressive des matériaux stratifiés et analyse de la tenue de structures composites. Besançon: Université de Franche-Conté; 2005.

[24] Albouy W. De la contribution de la visco-elasto-plasticité au comportement en fatigue de composites à matrice thermoplastique et thermodurcissable. Saint-Étienne-du-Rouvray: Normandie Université; 2013.

[25] Cognard J-Y. Numerical analysis of edge effects in adhesively-bonded assemblies application to the determination of the adhesive behavior. Comput. Struct. 2008;86:1704-1717.

[26] Bidaud P. Analysis of the cyclic behavior of an adhesive in an assembly for offshore windmills applications. Brest:Université de Bretagne Occidentale; 2012.

[27] Cognard J-Y, Créac'hcadec R, Sohier L, et al. Influence of adhesive thickness on the behaviour of bonded assemblies shear loadings using a modified TATS fixture. Int. J. Adhes. Adhes. 2010;30:257-266.

[28] Davies P, Sohier L, Cognard J, et al. Influence of the adhesive bondline thickness on joint strength. Int. J. Adhes. Adhes. 2009;29:724-736.

[29] Bidaud P, Créac'hcadec R, Thévenet D, et al. A prediction method of the behavior of adhesively bonded structures under cyclic shear loading based on a characterization of the viscous aspects of the adhesive in an assembly. J. Adhes. 2015;91:701-724.

[30] Maurice J. Characterization and modeling of the 3D elastic-plastic behavior of structural adhesive films for aeronautical applications. Brest: Université de Bretagne Occidentale; 2012.

[31] Créac'hcadec R. Analyse et modélisation du comportemenbt non linéaire d'assemblages collés pour application marine. Brest: Université de Bretagne Occidentale; 2008.

[32] Cowper GR, Symonds PS. Strain-hardenig and strain rate effects in the impact of cantilever beams. Providence: Brown University, Division of Applied Mathematics; 1957.

[33] Carrère N, Badulescu C, Cognard J-Y. Determination of the failure envelop on an adhesive using a modified arcan tests device - role of the plasticity and of the residualk stresses. Proceedings of the second international conference on structural adhesive bonding; 2013.

[34] Thevenet D, Créac'hcadec R, Sohier L, et al. Experimental analysis of the behavior of adhesively bonded joints under tensile/compression shear cyclic loadings. Int. J. Adhes. Adhes. 2013;44:15-25. 